Observatório das Desigualdades e-Working Paper N. o 3/2015

\title{
A Austeridade na Educação
}

Rosário Mauritti, Maria do Carmo Botelho, Nuno Nunes, Daniela Craveiro

Observatório das Desigualdades e-Working Papers (ISSN 2183-4199) Av. das Forças Armadas, Edifício ISCTE, 1649-026 LISBOA, PORTUGAL http://observatorio-das-desigualdades.com/ 
Rosário Mauritti, socióloga, professora auxiliar do ISCTE-IUL, investigadora do CIES-IUL. Maria do Carmo Botelho, professora auxiliar do ISCTE-IUL, investigadora associada do BRU-IUL. Nuno Nunes, sociólogo, investigador pós-doutoral do CIES-IUL.

Daniela Craveiro, doutoranda em sociologia pelo CECS-UM.

Título: A Austeridade na Educação

Resumo: Este estudo analisa alguns dos custos sociais das atuais políticas de austeridade económica, com especial enfoque no setor da educação. A pesquisa empírica está referenciada em dados institucionais relativos a um período alargado e incide particularmente sobre a situação portuguesa a partir de 2010, devido à notória inversão de tendências. Verifica-se que o Estado diminuiu a sua presença no setor da educação, garante do serviço público aberto e oferecido a todos, sem distinção. $O$ argumento nuclear que atravessa a análise, e para o qual se procura desenvolver alguns contributos substantivos, é o de que em função das soluções preconizadas na alocação de recursos e concretização de políticas, o limite económico real não é tanto o da escassez absoluta de recursos, mas o das prioridades da sua alocação.

Palavras-chave: Estado Social; Políticas de austeridade; Políticas redistributivas; Educação; Desigualdades; (Des)Emprego; Geração nem-nem.

Title: Austerity in education

Abstract: This study examines some social costs of current economic austerity policies, with special focus on education. Empirical research is referenced in institutional data relative to an extended period, and focuses particularly on the Portuguese situation since 2010, due to the remarkable reversal trends. It is found that the state has decreased its presence in the education sector, undermining the universality of public service, offered to all without distinction. The nuclear argument running through the analysis, and for which it seeks to develop some substantive contributions, is that according to the recommended solutions in resource allocation and implementation of policies, the real economic limit is not so much the absolute scarcity of resources but the priority of its allocation.

Keywords: Social state, austerity policies; redistributive policies; education; inequalities; (Un)Employment; NEET generation.

\section{Como citar este artigo}

Mauritti, R; Botelho, MC; Nunes, N; Craveiro, D (2015), "A Austeridade na Educação", Observatório das Desigualdades e-Working Papers, N.o 3/2015:3-20; ISCTE-IUL, CIES-IUL, ISSN 2183-4199

Disponível em http://wp.me/P4h6tu-p3. 
A presente pesquisa procura perceber em que medida as mudanças que têm vindo a ser implementadas no âmbito das políticas económicas de austeridade alteraram, ou não, o princípio de universalidade de direitos e as garantias associadas de acesso por parte de todos os cidadãos. Neste paper focaliza-se, especificamente, os efeitos sociais dessas políticas no setor da educação.

A análise tem por base alguns dados substantivos que apontam para a progressiva redução do Estado enquanto prestador de serviço direto na área da Educação, integrada no que Pierre Bourdieu (1998a) denominou como função da "mão esquerda".

As análises aqui desenvolvidas decorrem no âmbito do programa de investigação "Eficiência e equidade na construção do serviço público: a qualidade do Estado social em questão" (Estudos OD, CIES-IUL), e dão continuidade a um trabalho anterior sobre os processos de reconfiguração das "mãos do Estado" (cf. Botelho e outros, 2014 e 2015).

\section{O Estado português e a atual política orçamental}

O papel do Estado e a sua configuração têm sido alvo de acentuada discussão política, institucional e científica, perante as mudanças verificadas nos Estados sociais europeus ao longo das últimas décadas.

Pierre Bourdieu (1994, 2006 e 2012) é um autor fundamental para compreendermos as atuais tensões por que atravessam os Estados modernos. No seu entender, o Estado constitui o culminar de um processo de concentração das diferentes espécies de capital, o que lhe confere o meta-capital necessário para se impor sobre as outras espécies de capital e a sua (re)produção. A formação do Estado, com a constituição de um específico capital estatal, acompanha a construção do campo do poder, como espaço em que os detentores de diferentes espécies de capital lutam pelo seu controlo; Estado que se reforça através da articulação dos diversos campos administrativos que o integram.

A "mão esquerda" e a "mão direita" do Estado representam as funções dos Estados modernos e contemporâneos, postulado teórico explorado por Bourdieu (1998b e 2001) com forte incisividade na análise e compreensão das tensões com que os Estados se veem confrontados após a crise eclodida em 2008.

No entender de Pierre Bourdieu, o que caracteriza a mão direita do Estado? A concentração do capital de força física e a sua afirmação para o exterior de fronteiras, e internamente a vigilância das classes dominadas; os imperativos de defesa do território; 
a manutenção da ordem interna; a instauração de uma fiscalidade eficiente; a competição inter-estatal; o assegurar do mercado nacional; a concentração do capital jurídico que se efetiva pela constituição de um campo jurídico autónomo (Bourdieu, 1994, 1998b, 2006).

E o que define a mão esquerda do Estado? A incidência sobre os mecanismos da redistribuição; o exercício das funções ditas "sociais" em áreas que consubstanciam a universalidade de direitos fundamentais, como a saúde, a educação, a habitação, o emprego e a segurança social (Bourdieu, 1993, 1994, 1998b). Em suma, as áreas de ajuda direta às pessoas, de combate às desigualdades sociais, que procuram compensar efeitos e carências de roturas biográficas, e salvaguardam princípios de coesão social e participação cívica.

Como argumentado em Botelho e outros $(2014,2015)$, nas perceções dos cidadãos, no balanço que fazem entre a carga de contribuições sociais e de impostos e o retorno que obtêm dos serviços públicos, num contexto em que não se vivenciem situações extremas de guerra civil ou militar, são sobretudo estas componentes ligadas à mão esquerda aquelas que são positiva ou negativamente referenciadas como indicadores da qualidade do Estado. A diminuição acentuada destas componentes associadas à mão esquerda, sob a aparência e o jugo da inevitabilidade e da procura da eficiência (económica) do Estado, procederia a um corte radical entre o económico e o social e ao consequente abandono de um certo número de terrenos de ação social.

Nesta orientação, a mão direita, corporizada pelos grandes responsáveis dos Ministérios das Finanças e por uma burocracia administrativa orientada para o controlo e vigilância do cidadão, mais do que para o servir, extremaria a sua oposição face ao que Bourdieu intitula de "trabalhadores sociais", a mão esquerda do Estado. Ou seja, o conjunto dos servidores que representam no interior do próprio Estado as conquistas sociais da modernidade e a salvaguarda de direitos universais de dignidade e cidadania (Bourdieu, 1993 e 1998b).

Lamentavelmente, esta parece ser de facto a ideologia sectária, fundada numa serie de teorias falsas ou no mínimo arbitrárias, que vem sendo preconizada em Portugal, pelas instâncias de governação nacionais e internacionais.

Sobre a égide do liberalismo económico, o Estado é hoje apontado como um dos agentes de maior inoperância e estrangulamento das forças livres do mercado, e que mais contribuiu para uma certa incapacidade coletiva de adaptação e reação à "crise". Tal, ao mesmo tempo que numa teorização não demostrada empiricamente se associa, por um 
lado, a eficácia e "modernidade" ao empreendedorismo privado e, por outro lado, o arcaísmo e a ineficácia ao serviço público (Bourdieu, 1993).

Nesta linha argumentativa, a reestruturação do Estado através da diminuição de recursos humanos e materiais afetos ao setor público, secundada pela privatização dos serviços de prestação direta passíveis de rentabilização e acumulação do lucro (cf. documentos da TROIKA), é definida como um dos eixos prioritários das políticas neoliberais que têm vindo a ser implementadas, numa articulação cooperante entre a tríade internacional $^{1}$ e as instâncias de governação nacionais.

É neste quadro que se posiciona nomeadamente a política orçamental do documento Memorando de Entendimento sobre as Políticas de Condicionalidade Económica (MEPCE, 2011), plasmada nos seguintes princípios:

Relativamente à dotação financeira: Reduzir, em 2011, o défice das Administrações Públicas para menos de 10.068 milhões de euros, (equivalente a 5,9\% do PIB), e para menos 5.224 milhões de euros, em 2013 (3,0\% do PIB).

No que concerne aos serviços da administração: "reduzir o número de serviços"; (...) "avaliar periódica e regularmente a eficiência e eficácia (value for money) dos diversos serviços públicos que integram as Administrações Públicas"; "promover a mobilidade dos trabalhadores"; "reduzir as transferências do Estado para Serviços e Fundos Autónomos"; e "rever as políticas remuneratórias e as prestações acessórias (fringe benefits) das entidades prestadoras do serviço público" (MEPCE, 2011).

Neste processo pautado pelo objetivo prioritário de controlo orçamental e de redução da dívida e do défice públicos, e sob a égide de um discurso sectário de alegada racionalização das práticas de gestão orçamental, alguns dos mecanismos que asseguram a redistribuição e equidade na efetivação de direitos fundamentais de caráter tendencialmente universal - nomeadamente relativos à educação, à proteção da saúde e à segurança social -, foram profundamente alterados. ${ }^{2}$

No quadro 1, damos conta em linhas gerais da forma como tem sido levada a cabo a regulação da afetação de recursos humanos nas várias áreas funcionais associadas à mão esquerda e à mão direita do Estado.

\footnotetext{
${ }^{1}$ Comissão Europeia, Banco Central Europeu (BCE) e Fundo Monetário Internacional (FMI)

${ }^{2}$ Tal como foi aliás entretanto reconhecido quer por Christine Lagarde (em Junho de 2013, declarações publicadas nomeadamente no The Guardian, enquanto chefe do FMI), quer por Jean-Claude Juncker, presidente da Comissão Europeia, em Fevereiro de 2015, nas vésperas do termo de negociações que iriam definir as condições de continuidade, ou não, dos apoios estruturais prestados à Grécia.
} 
Em termos globais, desde 2005 o Estado português tem vindo a diminuir progressivamente em termos de número de efetivos que estão afetos aos serviços por ele prestados.

Quadro 1. Processos de reconfiguração das funções do Estado

\begin{tabular}{|c|c|c|c|c|c|c|c|c|}
\hline As mãos do Estado & 2005 & 2007 & 2008 & 2009 & 2010 & $2011 \perp$ & 2012 & $2013(p)$ \\
\hline Mão direita & 28,8 & 28,7 & 28,5 & 28,3 & 28,8 & 32,4 & 33,3 & 33,8 \\
\hline Finanças & 2,9 & 2,9 & 2,9 & 2,8 & 2,7 & 3,1 & 3,2 & 3,3 \\
\hline Relações externas & 0,5 & 0,6 & 0,6 & 0,6 & 0,7 & 0,8 & 0,9 & 0,8 \\
\hline Soguranco & & & & & & & & \\
\hline Defesa & 19,4 & 19,3 & 19,1 & 19,1 & 19,5 & 21,7 & 22,2 & 22,5 \\
\hline Justiça & 5,9 & 5,9 & 5,9 & 5,8 & 5,9 & 6,7 & 7,0 & 7,1 \\
\hline Mão e & 71,2 & 71,3 & 71,5 & 71,7 & 71,2 & 67,6 & 66,7 & 66,2 \\
\hline Educação e ciência & 42,4 & 44,5 & 45,5 & 46,4 & 46,5 & 53,5 & 52,6 & 51,9 \\
\hline Saúde & 20,0 & 19,0 & 18,5 & 18,0 & 17,6 & 7,4 & 7,3 & 7,4 \\
\hline $\begin{array}{l}\text { Economia, emprego e segurança } \\
\text { social }\end{array}$ & 8,8 & 7,8 & 7,5 & 7,2 & 7,1 & 6,8 & 6,8 & 6,9 \\
\hline Total (no de postos de trabalho) & 566329 & 529306 & 523117 & 522925 & 512424 & 441078 & 419247 & 402413 \\
\hline
\end{tabular}

Fonte: DGAEP, cálculos próprios.

Notas : $\perp$ Nova nomenclatura de classificação; (p) dados provisórios.

As tendências subjacentes evidenciam no primeiro arco temporal, entre 2005 a 2010, uma variação negativa relativamente equitativa das duas mãos. Particularmente, na mão esquerda - a mão que acolhe as funções sociais em destaque nesta análise. Neste período "pré-troika" uma análise mais detalhada permite verificar, já nesta fase, uma diminuição das funções ligadas à economia, emprego e segurança social (com quebras nas ordem dos $27 \%$ ) e também na saúde (-20\%). De forma concomitante, a educação e ciência, mantém-se uma área relativamente salvaguardada pela então governação socialista.

No segundo período, entre 2011 e 2013, num ciclo de governação de coligação governativa entre PSD e CDS-PP, tutelado pela troika, o aspeto mais notório é o reforço relativo da mão direita, onde o peso global de postos de trabalho aumenta 1,4 pontos percentuais, ocorrendo em todas as áreas com exceção das relações externas.

Se é verdade que mesmo estas componentes de funções do Estado são sujeitas ao processo de "racionalização de despesa" (leia-se diminuição), o facto de apresentarem genericamente uma tendência de quebra menos acentuada $(-4,8 \%$, contra $-10,7 \%$ da mão esquerda), contribuiu para o aumento do seu peso no todo da estrutura funcional do Estado (figura 1). 
Na governação tutelada a partir de 2011, o aspeto mais relevante é pois a diminuição transversal de todas as funções da mão-esquerda, mas em particular daquelas dedicadas à educação e ciência. Estas, como salientado em Botelho e outros (2014 e 2015) são particularmente afetadas nos fluxos de saída de trabalhadores por reforma ou aposentadoria (sensivelmente 37\% dos 16133 funcionários do Estado que se reformaram em 2013 estavam afetos a esta área).

Figura 1. As mãos do Estado: emprego Público em Portugal por grandes áreas funcionais (2005-2010; 2011-2013)

\section{Crescimento/Decréscimo (\%)}

Relações externas

Economia, emprego e segurançáde
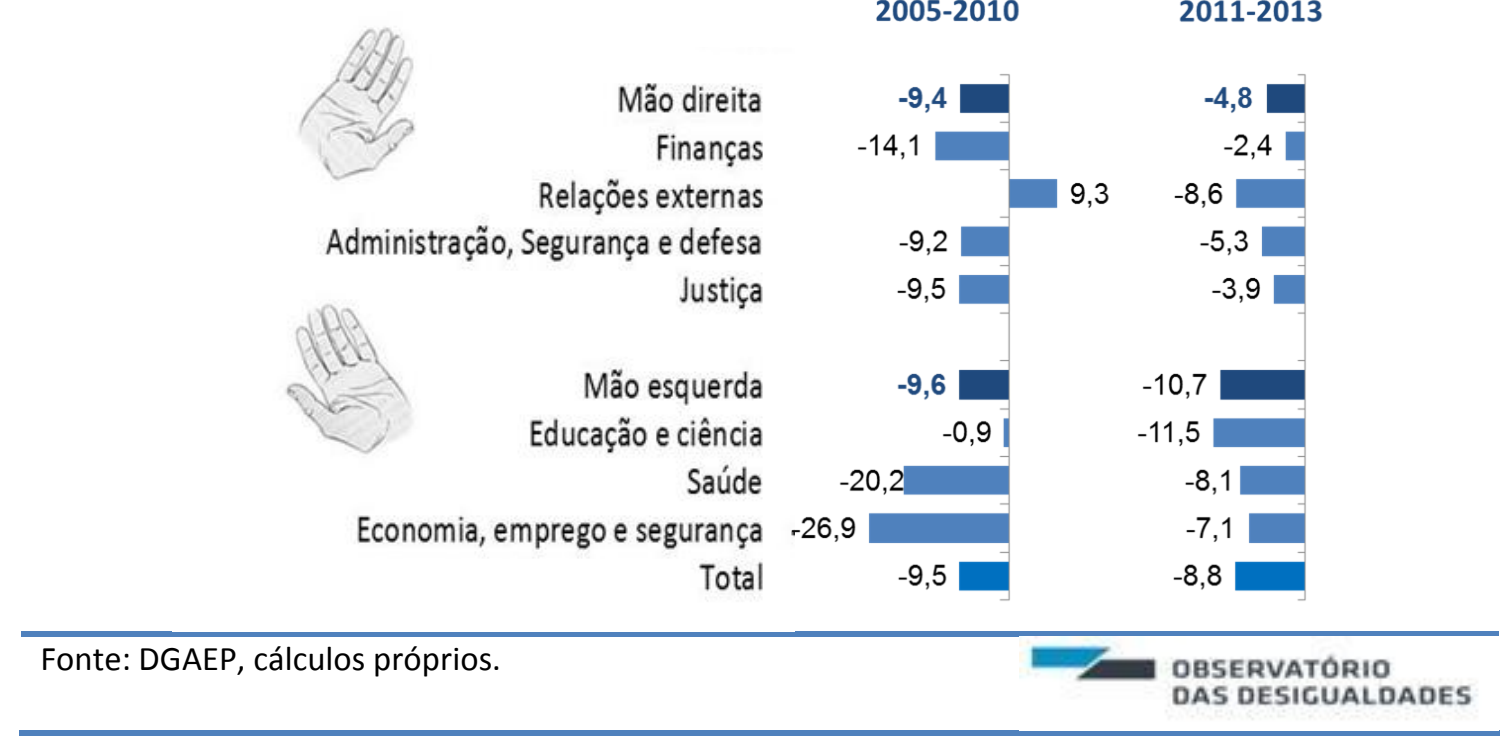

2005-2010

2011-2013

Mas como se refletem estas mudanças na distribuição de recursos humanos que prestam serviço público, relativamente à despesa pública? Na figura 2 começamos então a analisar a forma como têm vindo a ser priorizadas as intervenções do Estado na afetação direta de recursos monetários, segundo áreas funcionais.

No período 2010 a 2012, uma vez mais, confirma-se a tendência, já observada anteriormente, de recuo das duas mãos, embora também nestes dados sobre a despesa do Estado, esta seja uma tendência bastante mais acentuada nas funções da mão esquerda associadas à componente social e de solidariedade.

Tomando como unidade de medida milhões de euros, observamos que a redução de despesa nas várias componentes assinaladas na mão esquerda se aproxima dos 9 mil milhões de euros.

A saúde apresenta um recuo aproximado de $13 \%$, no todo de funções sociais desempenhadas pelos serviços da mão esquerda, ocupando a segunda posição nas 
tendências de descida. Quanto ao emprego, e de forma contraintuitiva, tendo em conta como se analisará adiante, o aumento exponencial do número de desempregados, e depois de anos seguidos pautados pelo sistemático aumento das prestações sociais de desemprego, assiste-se a um recuo das despesas nesta área, na ordem dos 10\% (-4170 milhões face ao montante global despendido em 2010).

Figura 2. Despesas do Estado: uma perspetiva comparativa das duas mãos (preços constantes de 2011)

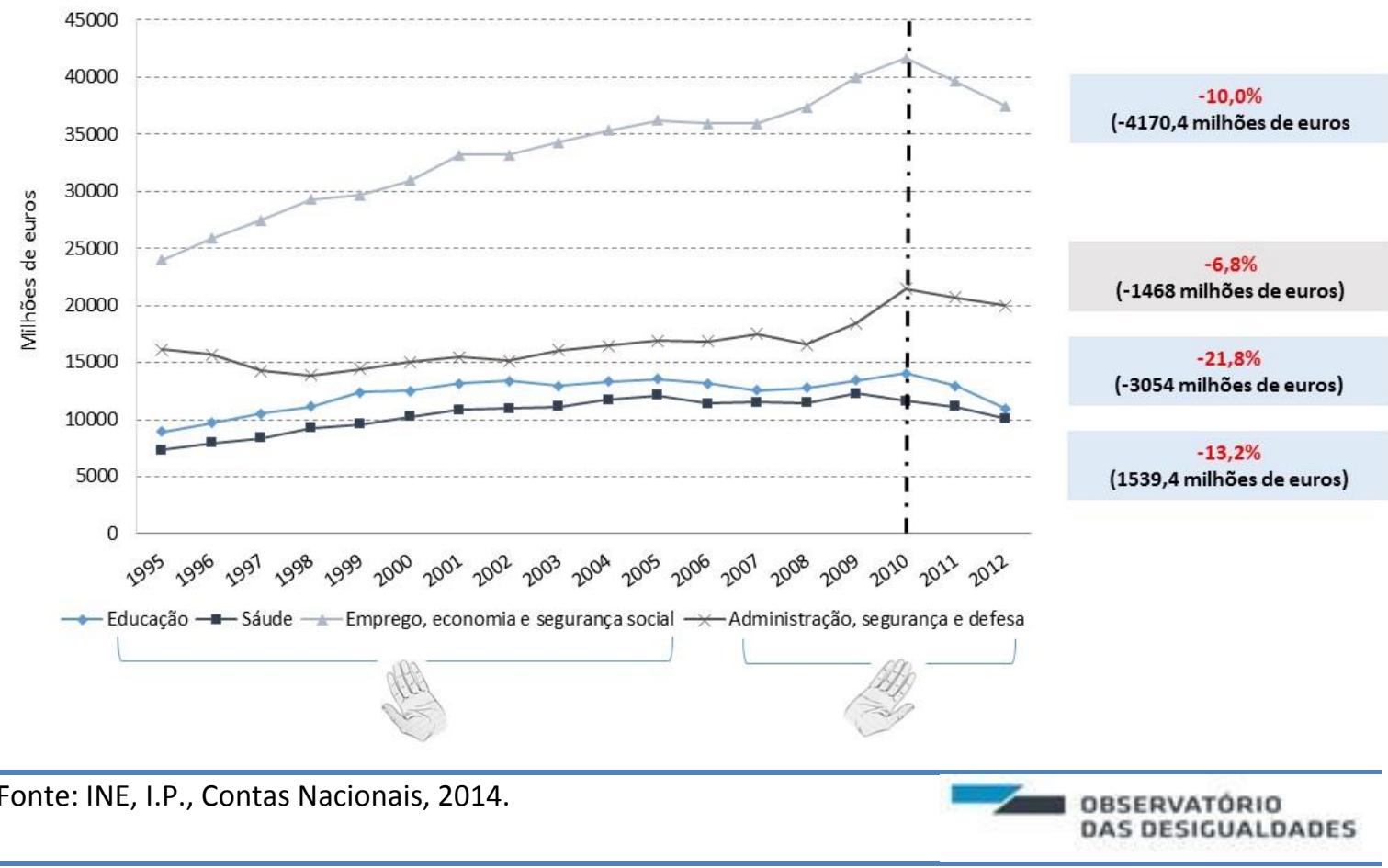

Mas o recuo da mão esquerda do Estado é particularmente expressivo na educação e ciência onde a diminuição de "despesas" (ou não devia dizer-se antes o investimento?), entre 2010 e 2012, ronda os 22\%, traduzindo pois uma redução acumulada de transferências do Estado para este setor na ordem dos três mil milhões de euros. Esta diminuição de investimento tem consequências que vão para além dos anos em que ocorrem, podendo comprometer a empregabilidade e o desenvolvimento da sociedade e do país. Por este facto, as alterações ocorridas na Educação e os efeitos na empregabilidade irão ser apresentadas em seguida, através da análise dos indicadores estruturais mais relevantes e atuais da agenda europeia.

\section{Efetivação de direitos no acesso à educação}

Em Portugal, o recuo do Estado na educação segue de perto o Memorando de Entendimento sobre as Políticas de Condicionalidade Económica, o qual ao nível da 
despesa previa a "racionalização do sector da educação e da rede de escolas" tendo em vista a poupança acumulada de 380 milhões. É neste contexto que se enquadra o forte recuo do Estado na educação, o qual, nesta área é colmatado pelo reforço de consumos por parte das famílias (ver figura 3).

Figura 3. O Estado na educação (Preços constantes de 2011)

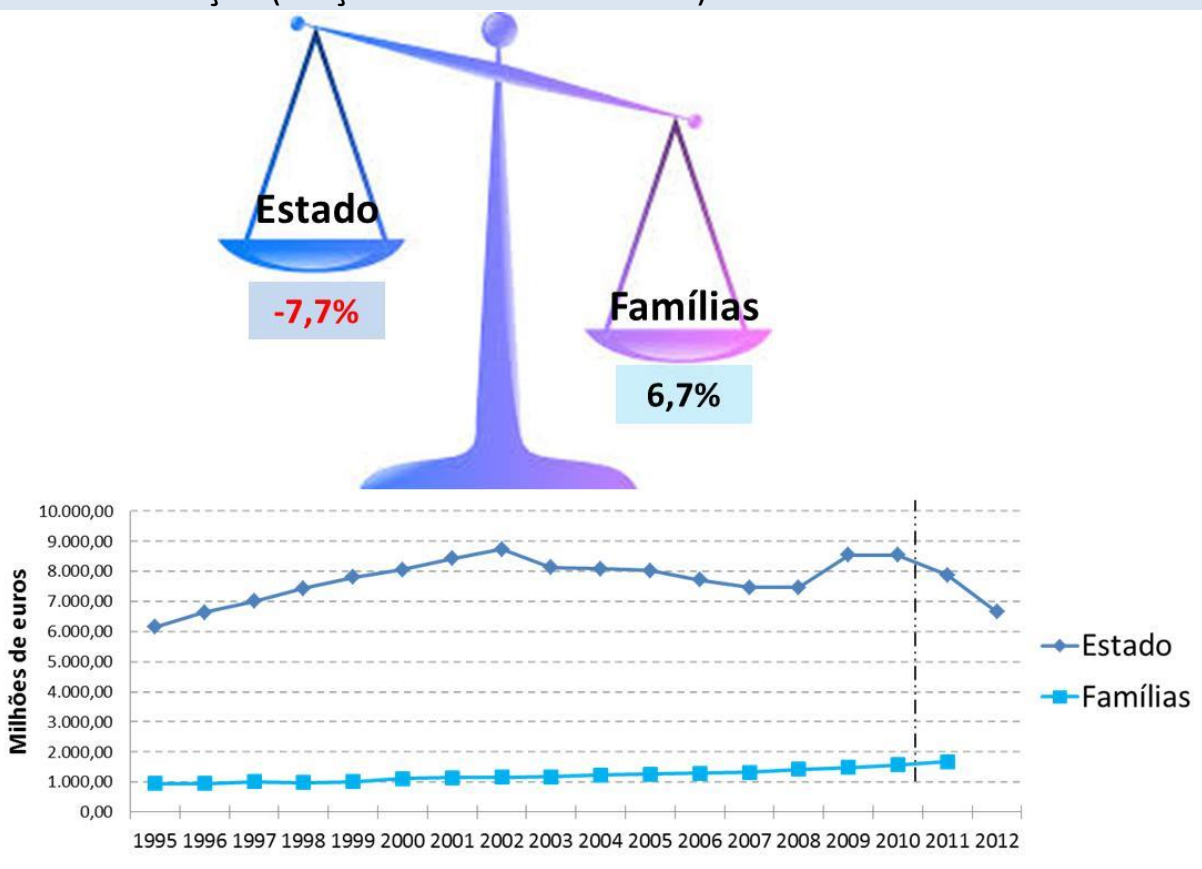

Fonte: DGO/MEF - Relatório/publicação "Conta Geral do Estado", INE - Contas Nacionais Anuais (Base 2011), PORDATA, 2015.

OBSERVATORIO DAS DESIGUALDAdES

É certo que não se pode retirar deste recuo do Estado na educação uma ilação imediata de retrocesso face às metas definidas em matéria de política educativa. Para tal aferição, uma das questões nucleares em análise é saber em que medida Portugal, mesmo neste contexto, conseguiu concretizar o equilíbrio entre redução de despesa em educação e manutenção dos objetivos assumidos nomeadamente perante os portugueses e parceiros europeus (em particular a Comissão Europeia), tendo em vista a convergência com os padrões médios europeus. Ou, dito de outra forma, em que medida, conseguiu progredir num ajustamento estrutural dos perfis qualificacionais das várias gerações de crianças, jovens e população em idade ativa, capacitando-se para uma participação efetiva nas dinâmicas contemporâneas de uma "sociedade do conhecimento e da informação"?

Nesta análise começamos por observar um dos indicadores utilizados para monitorizar a performance dos estados membros na concretização da Agenda 2020: a evolução das taxas reais de escolarização. Estas dão-nos a proporção de jovens que 
participam no sistema escolar dentro do coorte geracional em que é esperada essa participação.

É lugar-comum - mesmo entre cidadãos "informados" - que hoje em Portugal a massificação da escolarização pelo menos nas gerações em idade escolar constitui uma meta absolutamente atingida.

Os dados que apresentamos na figura 4 não confirmam tal, muito pelo contrário: não atingimos ainda sequer $100 \%$ de escolarização real no ensino básico ( $3^{\circ}$ ciclo), e é particularmente preocupante observar que esta taxa está a decair; no secundário temos 3/4 dos jovens neste nível de escolaridade e no superior apenas cerca de 1/4.

Figura 4. Taxa real de escolarização por nível de ensino

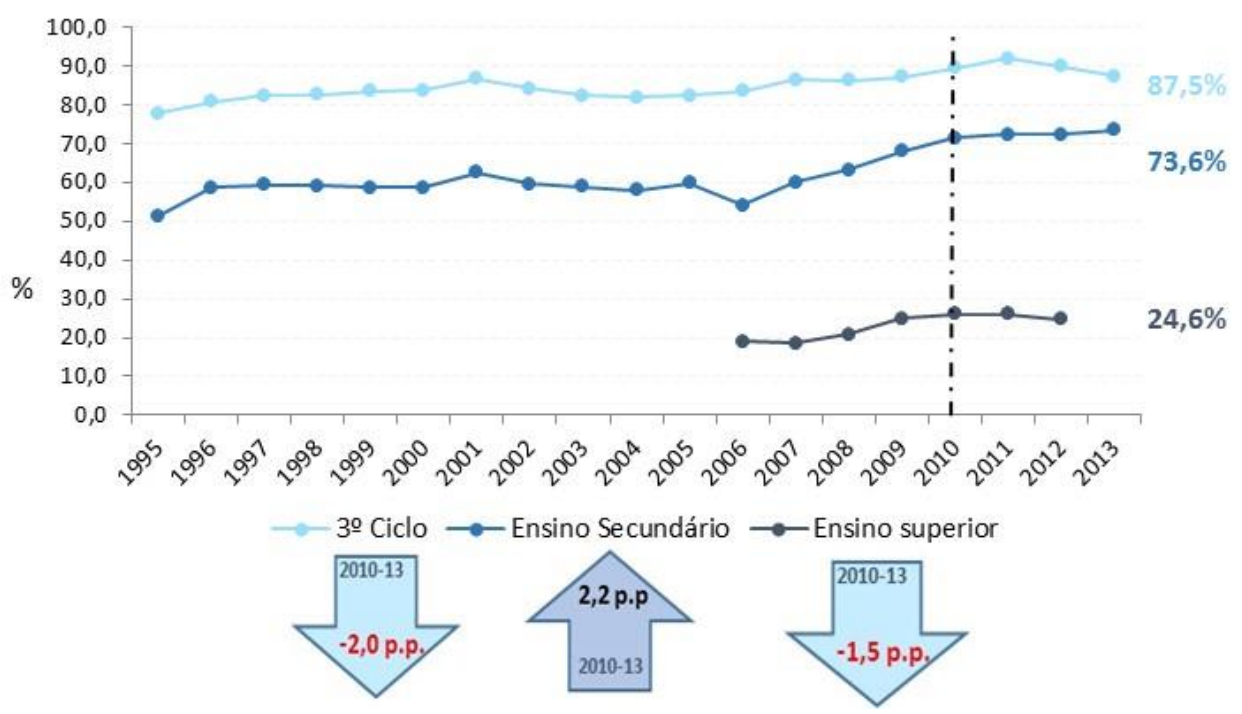

Fonte: DGEEC/MEC; INE, PORDATA, 2015.

Apesar disto, a figura 5 permite-nos olhar para o longo caminho percorrido de convergência face aos padrões de qualificação europeus, particularmente nas gerações mais jovens da população ativa. Este aumento da escolaridade dos mais novos não é contudo suficiente para compensar os baixos perfis de qualificação dos mais velhos.

A distância face aos padrões europeus é, assim, ainda significativa (cf. Martins e outros, 2014; Costa e outros, 2015). Como tal, assumindo que os restantes países membros da UE, hoje com padrões melhorados de escolarização das suas populações, mantêm tendências de crescimento, o recuo ou pelo menos estagnação em Portugal traduzível, por exemplo, num fraco investimento na qualificação da população adulta 
(CNE, 2014) - consubstancia um agravamento do risco de empobrecimento estrutural e incapacitação de reação futura.

Figura 5. População com pelo menos o ensino secundário, em Portugal e na UE ( 25 a 34 anos e 25 a 64 anos)

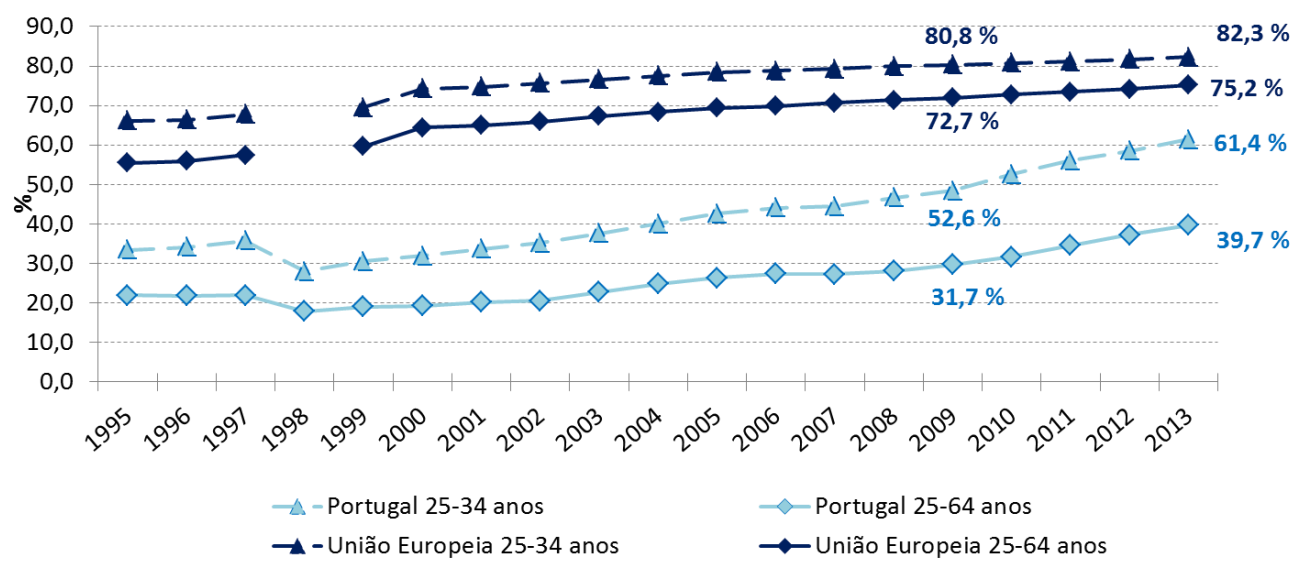

Fonte: EUROSTAT, 2015.

DBSERVATORIO

O abandono escolar ${ }^{3}$ é outro dos indicadores selecionados no plano europeu para monitorizar o comportamento dos países relativamente aos compromissos assumidos na Agenda 2020. Nesta matéria a convergência com a Europa tem sido também notória. No período de apogeu da crise, abrangido pelo programa de ajustamento económico e financeiro, Portugal manteve ritmos expressivos de diminuição do abandono escolar, atenuados nos últimos três anos sobretudo pelo comportamento feminino, que estabiliza quando quase atinge o limiar que caracteriza o todo Europeu.

Em termos globais, no ano 2014 a taxa de abandono escolar em Portugal rondava os $18 \%$ (21\% para o sexo masculino), evidenciando, pois, alguma persistência de níveis relevantes do fenómeno. Na Europa, no mesmo ano 2014, esse patamar era de $11 \%$ e $13 \%$, respetivamente (figura 6). Significa que há que insistir no esforço de mobilização dos jovens na escolarização, especialmente quando existem ainda segmentos relevantes que continuam a ser excluídos de forma precoce do sistema (cf. Álvares e outros, 2014; Alvarez, Costa e Castro, 2014).

${ }^{3}$ População com idade entre 18 e 24 anos, sem o secundário completo, que completou o $3 .^{\circ}$ ciclo de escolaridade ou não, e que não está inserida em qualquer programa de educação/formação. 


\section{Figura 6. Abandono escolar precoce}

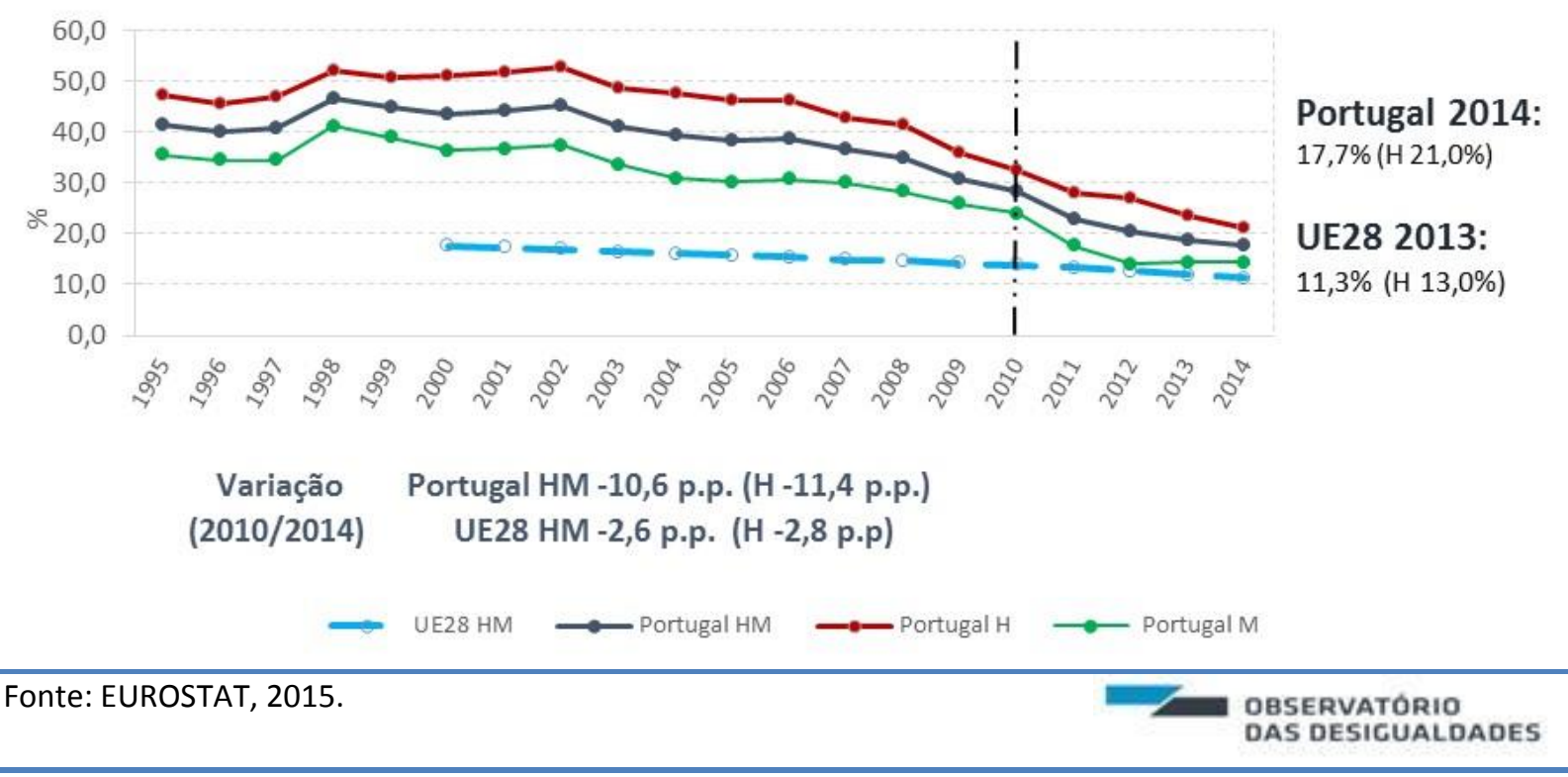

Assim, e apesar de a educação ou de forma mais abrangente a qualificação dos portugueses ser uma das áreas que apresenta melhorias expressivas, ao longo das últimas décadas, a verdade é que a evolução recente relativamente a alguns indicadores sugere que o risco de divergência face aos padrões médios europeus, pela reversibilidade de tendências, se está de facto a agravar. É exemplo, a situação, já assinalada, de recuo de escolarização real desde logo, ao nível do ensino básico - muito coadjuvado também pelo número "excessivo" de retenções que se observam neste primeiro patamar de escolarização (CNE, 2015, página de apresentação do relatório):

"Em Portugal existem atualmente mais de 150000 alunos que ficam retidos no mesmo ano de escolaridade. De acordo com os dados do PISA 2012, cerca de 35\% dos jovens portugueses com 15 anos tinham já sido retidos pelo menos uma vez, contra a média OCDE de 13\%, e mais de 7,5\% apresentam no seu percurso mais de uma retenção."

Em relação ao ensino superior, não obstante o alargamento a que assistimos, em Portugal sobretudo a partir da segunda metade dos anos 80 e ao longo da década de 90 , Portugal está ainda longe de ser "um país de doutores". Este discurso tem sido amiúde veiculado como explicação e justificativo para a diminuição da participação do Estado neste nível de ensino (participação que também marcou forte presença no setor particular e cooperativo).

Um dos reflexos destas orientações fica aqui muito evidente com as taxas de variação negativas que se observam, de forma muito nítida sobretudo no ensino superior 
privado, o qual a manter-se a tendência corre o risco de passar a assumir uma oferta puramente residual (figura 7).

Neste refreamento da procura de qualificações especializadas de nível superior, num contexto onde estamos ainda longe de ter atingido proporções de licenciados minimamente ajustadas àquele que é o padrão médio da União Europeia, articulam-se diversos fatores. Um primeiro decorre, desde logo, de questões materiais, ligadas ao empobrecimento geral das famílias. E sobretudo daquelas com menores recursos e que hoje têm indicações cada vez mais contraditórias sobre o valor do diploma como garantia de sucesso profissional futuro dos seus filhos - este é um fator tanto mais relevante quanto são elas, as famílias, a principal fonte de financiamento dos estudos neste patamar de ensino (Martins, Mauritti e Costa, 2005 e 2008).

Segundo o estudo realizado por Cerdeira e outros (2012), os custos anuais das famílias portuguesas com a educação representavam $22 \%$ da mediana do rendimento português, no ano letivo de 2010/2011, o que colocava Portugal em $10 .^{\circ}$ lugar numa lista de 16 países, atrás da Noruega, que liderava o ranking com apenas 2,2\%, da Dinamarca $(2,3 \%)$, França $(2,8 \%)$, Alemanha (4,2\%) e Inglaterra (21,5\%). Neste ranking, Portugal tem assim um posicionamento relativo mais próximo de países onde a frequência do ensino superior é mais “pesado" para as famílias - como são os casos dos Estados Unidos e do Japão.

Desde 2010/2011, com o aumento das despesas das famílias com educação e diminuição do rendimento (na ordem de 3,8 p.p. de 2011 a 2014 ${ }^{4}$ ), observa-se uma tendência de crescimento do peso do custo de um filho no ensino superior. Tal contribui para agravar as desigualdades de oportunidades e a injustiça social do ensino superior no país, reiteradamente assinaladas num passado anterior à crise, apesar do alargamento do sistema (Almeida e outros 2003; Martins, Mauritti e Costa 2005 e 2008).

Outro fator na decisão de prosseguimento dos estudos baseia-se, muitas vezes, nas duas opções que são equacionadas: concluir uma formação de nível superior, prolongando a dependência face à família de origem ou antecipar o ingresso numa atividade laboral, o que constitui um elemento dissuasor de avanço nos estudos. Estas opções poderiam eventualmente ser equacionadas em concomitância, contudo no panorama cultural prevalecente em Portugal, de dissociação entre atividades de estudo e participação económica no mercado laboral, são ainda percecionadas como mutuamente exclusivas.

\footnotetext{
${ }^{4}$ Fonte: Rendimento médio disponível das famílias, Pordata (acesso em maio de 2015).
} 
Mas nas perspetivas dos jovens e suas famílias, entre os argumentos que mais pesam, e que têm vindo a adquirir maior presença nos media, há dois que tenderão a destacar-se: um diz respeito ao aumento do desemprego de licenciados, o outro, também muito empolado, estabelece a relação entre excesso de diplomados e incremento dos fluxos emigratórios envolvendo jovens recém-licenciados - mesmo que, na massa global dos que emigram, afinal, o peso relativo dos que detêm um diploma esteja em consonância com o peso deste segmento na população total (cf. Pires e outros, 2014).

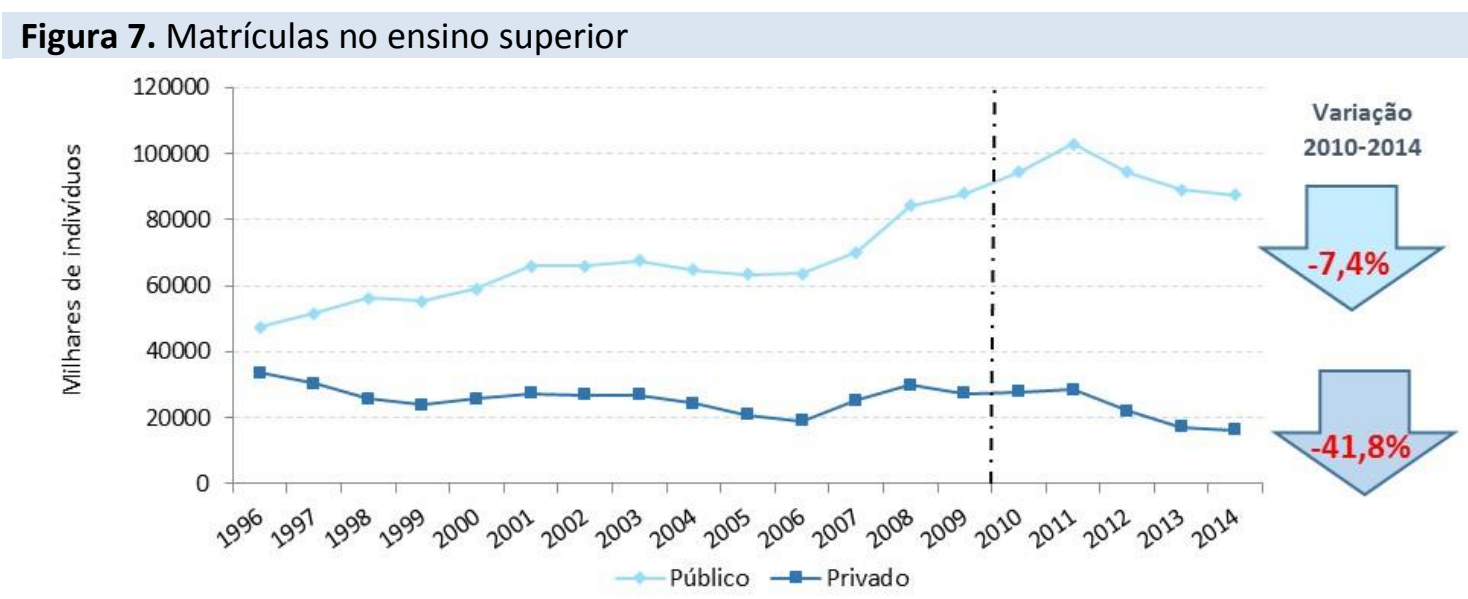

\section{A importância das qualificações no reforço da resiliência e capacitação social e económica}

A escolarização é hoje nas sociedades de conhecimento e informação, notoriamente, um dos elementos estruturais de promoção de equidade e capacitação global dos cidadãos para o exercício pleno de cidadania (Martins e outros, 2014; Nunes, 2013). Tal não apenas nas componentes de mobilização política e nos aspetos lúdicos e culturais, mas também, e de forma muito profunda na capacitação para a autonomia e livre arbítrio, consubstanciada nomeadamente através da participação plena no trabalho e no acesso à remuneração.

Num contributo parcial para a abordagem destas questões, a figura 8 dá destaque ao peso de jovens com 20 a 34 anos que abandonaram o sistema escolar há pelo menos cinco anos e que entretanto não estudam, não trabalham e não estão ativamente mobilizados na procura de trabalho, segundo o nível de qualificações adquiridas. $\mathrm{Na}$ 
titulação da figura destaca-se um dos designativos utilizados para a referenciação deste segmento populacional: "geração nem-nem": nem estudam, nem trabalham.

Figura 8. Geração "nem-nem" (inativos), segundo o nível de escolaridade atingido (20-34 anos)

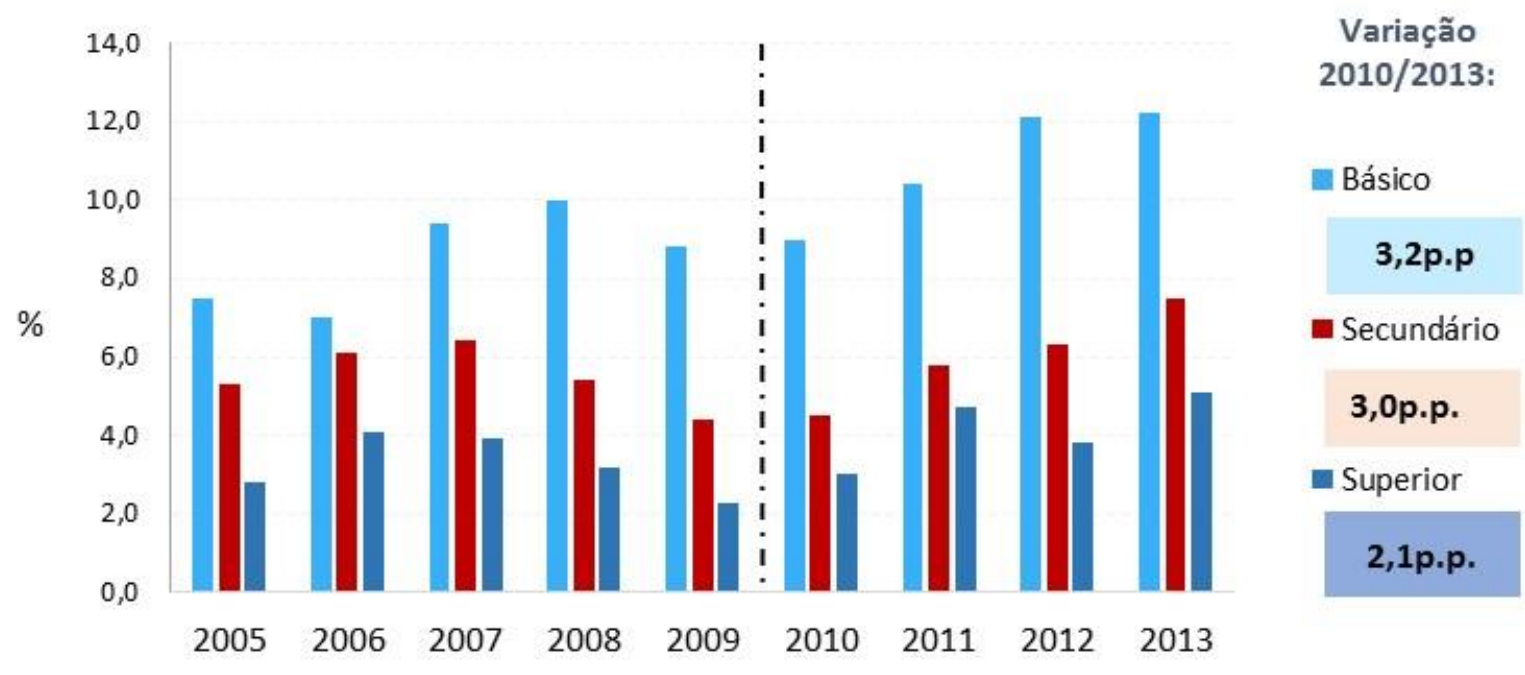

Fonte: EUROSTAT, Base de Dados em Linha (acesso Janeiro 2015).

Este é um setor da sociedade formado por jovens sem projetos de presente e eventualmente de futuro (Alves et al., 2011). O seu peso tem vindo a aumentar em todos os segmentos de qualificações (entre dois e três pontos percentuais, entre 2010 e 2013), e é particularmente expressivo junto dos que saíram do sistema escolar logo no limiar de educação correspondente ao nível básico (cerca de $12 \%$ no respetivo coorte geracional).

Em complemento dos dados anteriores, a figura 9 perspetiva outro segmento da "geração nem-nem", em termos quantitativos mais expressivo do que o anterior, respeitante aos que saíram do sistema escolar, não trabalham mas integram a população economicamente ativa, na medida em que estão disponíveis para exercer uma atividade.

No período entre 2010 e 2013 a percentagem de jovens com idades entre 20 a 34 anos que estão mobilizados numa procura de trabalho e não conseguem colocação é bastante expressiva em todos os segmentos de escolarização, mas particularmente no nível básico (no seio dos quais mais de 1/3 estão nesta situação). Entre 2012 e 2013 a diminuição relativa (ainda que ligeira) deste conjunto deve-se sobretudo a estes menos escolarizados, não sabemos se pela sua integração laboral, se - mais provável - pela 
transição destes para o segmento, sempre mais invisível na mediação que se faz destes comportamentos, para a população de "nem-nem" inativos.

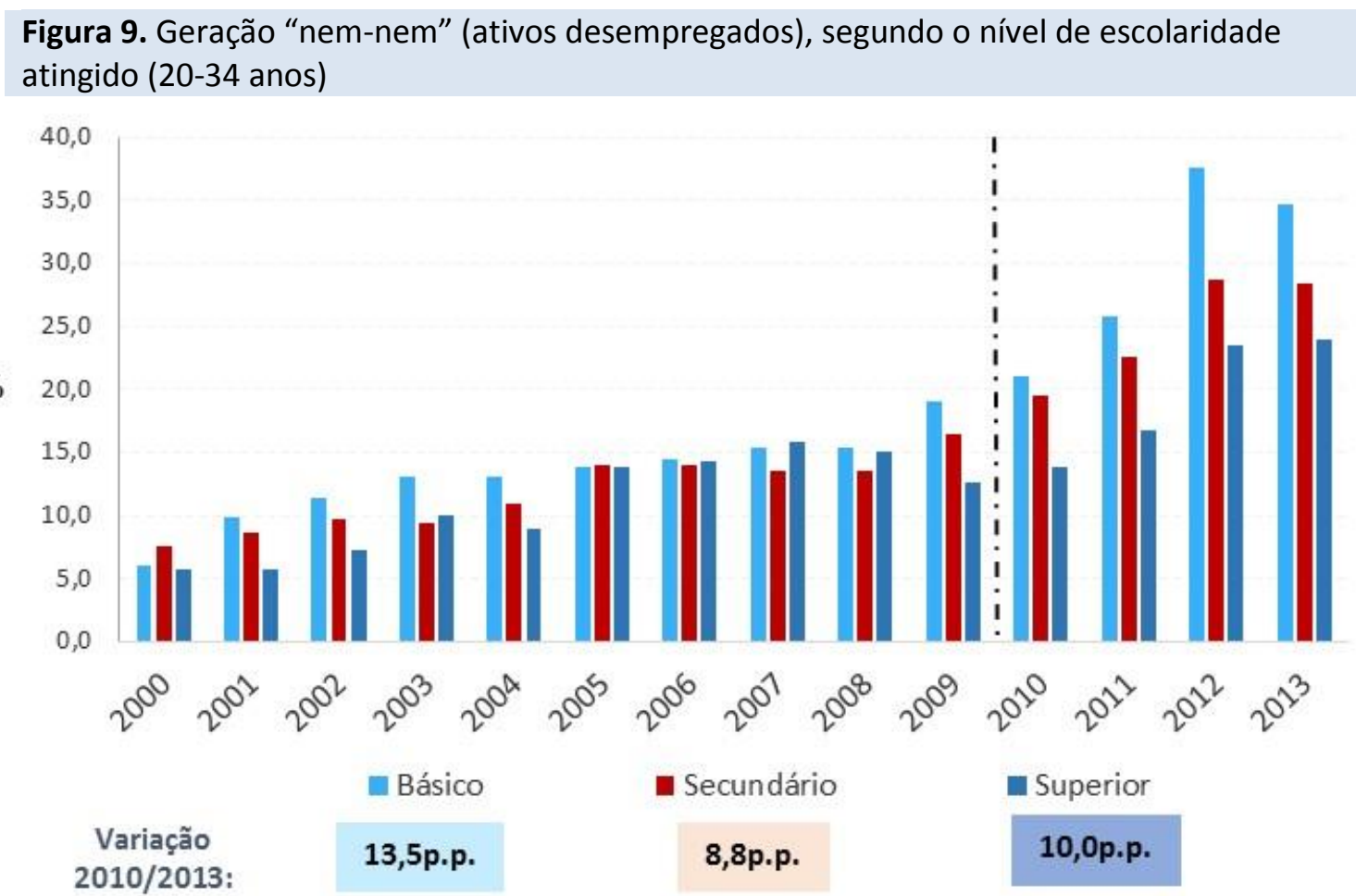

Fonte: EUROSTAT, Base de Dados em Linha (acesso Janeiro 2015).

Neste período, no conjunto de jovens com perfis de escolarização superior - muito melhorados no contex to da população ativa em Portugal - aumenta em cerca de 10 pontos percentuais os que não conseguem uma inserção económica qualificante, apesar de estarem disponíveis para tal. É um sinal claro de estagnação económica de um país que não consegue renovar-se aproveitando em pleno uma massa bem preparada de jovens adultos que querem nele contribuir.

De resto, tais experiências replicam-se - embora de forma menos acentuada - no todo da população ativa, referenciada na figura 10 nas idades de 25 a 64 anos. Estes dados, talvez até mais do que os anteriores, vêm assinalar uma clara alteração no relevo que é atribuído aos perfis de escolarização pela economia, em Portugal, desde sensivelmente 2003, ano a partir do qual a probabilidade de cair no desemprego passa a estar significativamente relacionada com os perfis de escolarização, isto numa relação inversa: quanto mais escolaridade menor a probabilidade relativa de cair em desemprego. 
O cenário de desemprego é preocupante, mas deve ainda ser realçado que nos números contabilizados fora do desemprego existem situações precárias, como sejam, o subemprego.

Figura 10. Taxa de desemprego, por nível de escolaridade (25 a 64 anos)

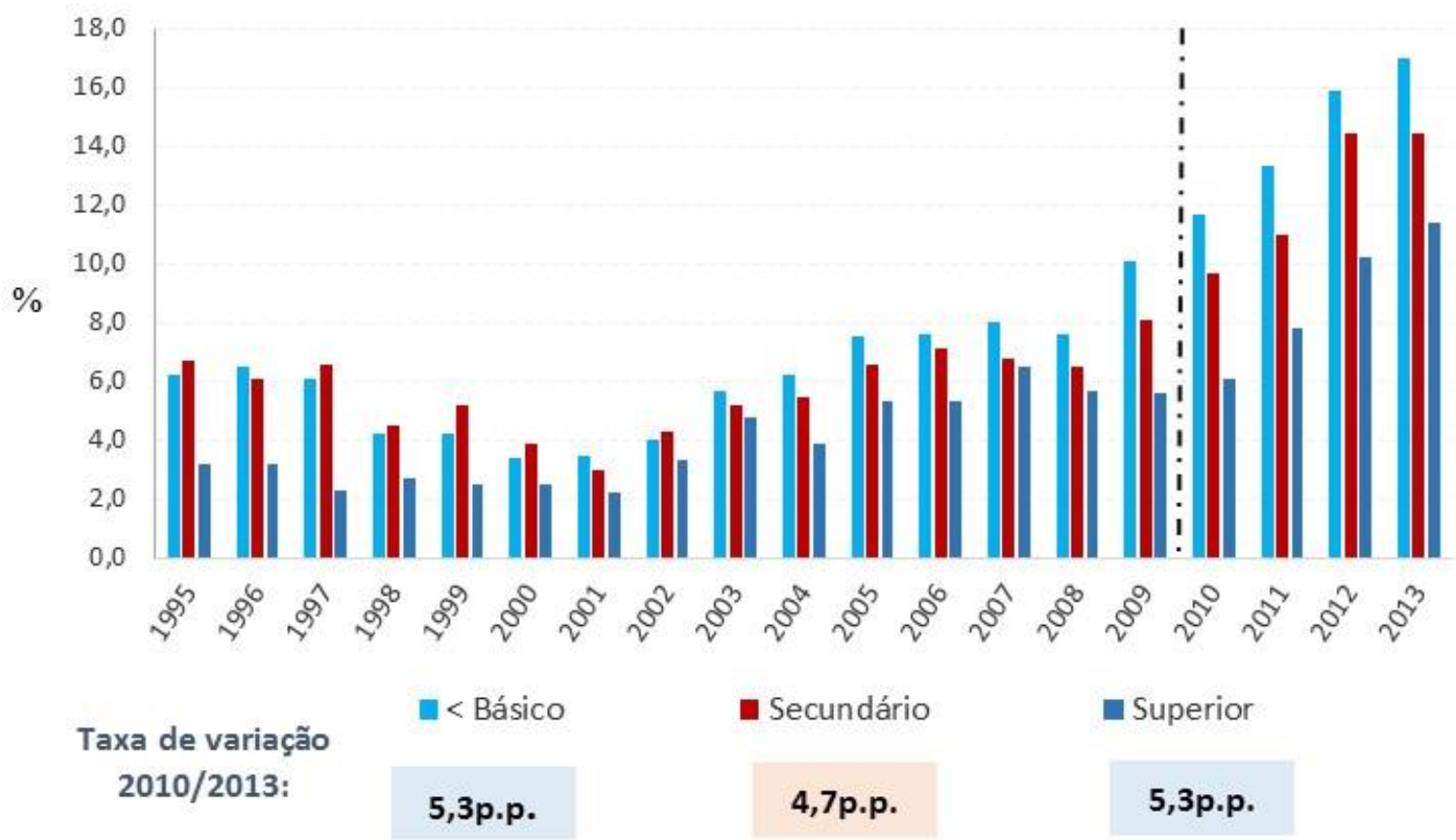

Fonte: EUROSTAT, Base de Dados em Linha (acesso Janeiro 2015).

Na figura 11 é possível observar os segmentos de trabalhadores que exercem a sua atividade a tempo parcial (parte dos quais, não necessariamente por opção), e os segmentos de cidadãos "desencorajados", disponíveis para trabalhar mas que desistiram de procurar, em função do nível de habilitações.

Qualquer uma das situações retratadas correspondem a indivíduos que não integram a população ativa desempregada nas estatísticas oficiais veiculadas pelo Instituto Nacional de Estatística ou pelo Eurostat - mesmo quando se apresentam e são classificados para efeitos de acesso a benefícios sociais de desemprego nessa condição de desempregados.

Verifica-se mais uma vez que os indivíduos que surgem em maior número em situação de subemprego ou que já não procuram emprego apresentam habilitações apenas ao nível do básico. Os indivíduos com o ensino superior apresentam-se com uma menor incidência nestas situações.

Os baixos perfis de escolarização destes dois segmentos (subemprego e não procura de trabalho) apontam novamente no mesmo sentido das análises anteriores: estudar 
compensa e constitui um fator estrutural que demarca claramente experiências presentes e futuras de resiliência e capacitação para a participação social e económica.

Figura 11. Número de indivíduos em situação de subemprego e ativos disponíveis que não procuram trabalho
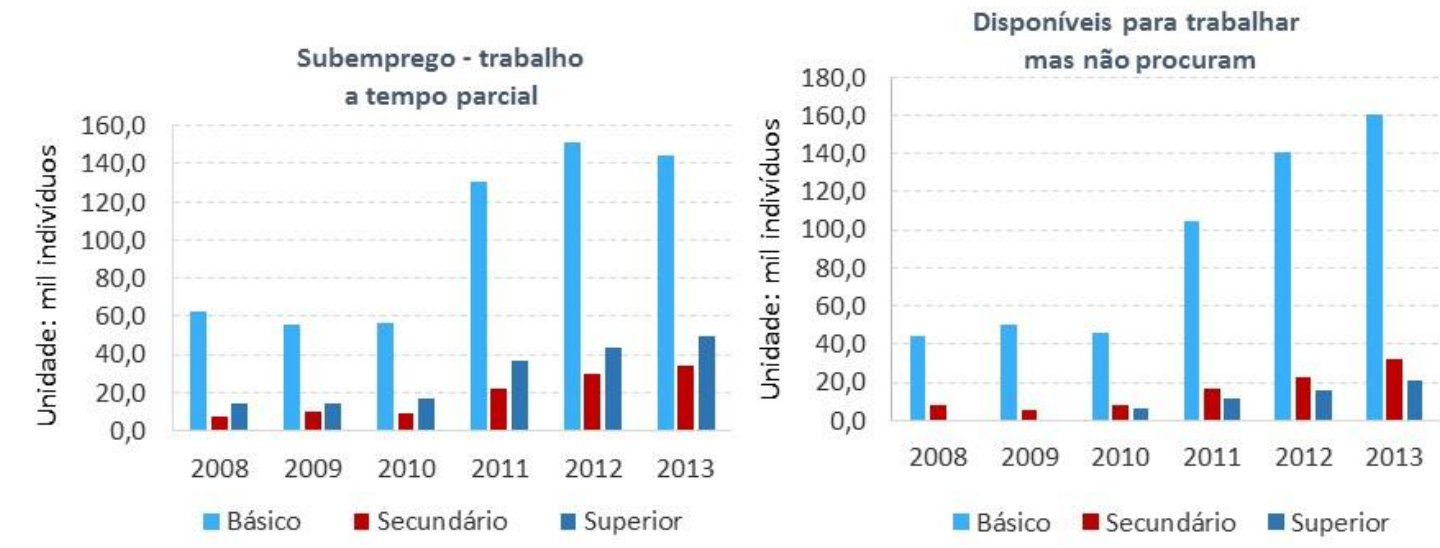

Fonte: EUROSTAT, Base de Dados em Linha (acesso Janeiro 2015).

OBSERVATORIO DAS DESIGUALDADES

\section{Conclusão}

As políticas de austeridade em Portugal constituem o universo agregado de políticas de desigualdade impostas ao país a partir de 2011, concretizadas institucionalmente enquanto políticas de classe (Carmo e Costa, 2015).

A meta-teoria e teoria de Bourdieu aplicáveis aos Estados contemporâneos são uma ferramenta interpretativa, muito profícua, das políticas de desigualdade e das políticas de classe, ainda oriundas do século XX, mas que com o eclodir da crise, são generativamente corporizadas em políticas de austeridade, adotadas em vários países e oficialmente consagradas pelas instituições europeias.

No contexto europeu e nacional, são visíveis as tensões entre as conquistas sociais (da mão-esquerda) e a obsessão transnacional europeia - validada no plano nacional por setores liberais e neoliberais - pelos equilíbrios financeiros e as restrições orçamentais (a mão-direita).

Este estudo focou estes processos no setor da educação. A análise desenvolvida permite concluir que esta área tem sido particularmente afetada pelas consequências da aplicação das políticas de austeridade, mormente, ao nível da política orçamental do Estado português, que, reduzindo o investimento público educativo, "obrigou” as famílias a suportarem mais custos em educação, que, por efeito indireto da crise económica e social e da sua redução de rendimentos, se tornaram ainda mais onerosos. 
Desta forma, a evolução positiva registada neste domínio nas últimas décadas relativamente a alguns indicadores, muito apoiada no investimento público, dá hoje sinais preocupantes de algum recuo, concomitante com a diminuição do Estado neste setor. Os crónicos défices educativo e de qualificações poderão agravar-se com as atuais tendências de aumento das desigualdades, de escassez de recursos económicos, de desregulação do mercado de trabalho e de desproteção por parte do Estado Social.

Os efeitos dolorosos desta política no estrangulamento da capacitação para o emprego qualificante e através deste - enquanto meio material nuclear de acesso a recursos - para concretização de projetos de vida por parte de jovens cidadãos que experimentam a transição para a vida adulta são também notórios, como vimos.

A exaltação de um modelo liberal que promove a concentração do rendimento, reivindica o incremento da produtividade, da competitividade e do lucro, ao mesmo tempo que assume as desigualdades sociais como inevitáveis e portanto o seu combate como ineficaz impera na visão dominante.

Um desafio fundamental permanece assim em aberto: Como assegurar a universalidade dos princípios fundamentais do nosso Estado de direito sob as atuais condições da globalização corporativa dos instrumentos de regulação política e financeira, e de imposição arbitrária de empobrecimento e degradação estrutural das nossas condições de vida?

\section{Referências bibliográficas}

Álvares, M (org.); Calado, A; Estevão, P; Merlini S; Nalha F (2014), Combate ao Abandono Escolar Precoce: Políticas e Práticas, Sumário Executivo Projeto POAT, Lisboa, ISCTEIUL, CIES-IUL.

Alvarez, D; Costa, MC; Castro, J (2014), Relatório Anual de avaliação da atividade das CPCJ no ano de 2013, Lisboa, Comissão Nacional de Proteção das Crianças e jovens em Risco.

Alves, NA; Cantante, F; Baptista, I; Carmo, RM (2011), Jovens em Transições Precárias. Trabalho, Quotidiano e Futuro, Lisboa, Editora Mundos Sociais.

Bourdieu, P (2012), Sur l'État. Cours au Collège de France 1989-1992, Paris: Seuil.

Bourdieu, P (2006), As Estruturas Sociais da Economia, Porto, Campo das Letras.

Bourdieu, P (2001), Contrafogos 2 : Por Um Movimento Social Europeu, Oeiras, Celta Editora.

Bourdieu, P (1998b), Contrafogos, Oeiras, Celta Editora.

Bourdieu, P (1998a), Meditações Pascalianas, Oeiras, Celta Editora.

Bourdieu, P (1994), Raisons Pratiques: sur la Théorie de l'Action, Paris, Éditions du Seuil.

Bourdieu, P (org.) (1993), La Misère du Monde, Paris, Éditions du Seuil.

Botelho, MC; Nunes, N; Mauritti, R; Craveiro, D (2015), "Tendências de mudança das funções do Estado em Portugal" em R.M. do Carmo e A F. Costa (org.), op.cit. 
Botelho, MC; Mauritti, R; Nunes, N; Craveiro, D (2014), "A mão esquerda e a mão direita do Estado português: que atuais tendências?”, Observatório das Desigualdades e-Working Paper N. ${ }^{\circ} 4 / 2014$.

Carmo, RM; Costa, AF (orgs.) (2015), Desigualdades em Questão. Análises e Problemáticas, Lisboa, Editora Mundos Sociais.

Cerdeira, L; Patrocinio, T; Cabrito, B; Machado-Taylor; Brites, R (2013), Higher Education CostSharing Policy: The Portuguese Case. In Larry Robert Smith (Ed), Higher Education: Recent Trends, Emerging Issues and Future Outlook, New York, Nova Publishers, pp 131147.

CNE (2014), O Estado da Educação 2013, Lisboa, Conselho Nacional de Educação.

CNE (2015), Recomendação sobre Retenção Escolar no Ensino Básico e Secundário, Relatório Técnico. Disponível em http://www.cnedu.pt/content/noticias/CNE/Relatorio_Tecnico_Retencao.pdf.

Costa FC; Mauritti, R; Martins, SC; Nunes, N; Romão, AL (2015), "A Constituição de um Espaço Europeu de Desigualdades", Observatório das Desigualdades e-Working Papers, N. 1/2015: 1-21.

Martins, SC; Nunes, N; Mauritti, R; Costa, AF (2014), "O que nos dizem as desigualdades educacionais sobre as outras desigualdades? Uma perspetiva comparada à escala europeia", in B. Portugal e Melo et al (orgs.), Entre Crise e Euforia: Práticas e políticas educativas no Brasil e em Portugal, Porto, FLUP, ISBN: 978-989-8648-40-2

Martins, SC; Mauritti, R; Costa, AF (2008), Estudantes do Ensino Superior: Inquérito às Condições Socioeconómicas, 2007, Lisboa, DGES/MCTES, Colecção Temas e Estudos de Acção Social (vol. 7).

Martins, SC; Mauritti, R; Costa, AF (2005), Condições Socioeconómicas dos Estudantes do Ensino Superior em Portugal, Lisboa, DGES/MCTES e CIES Lisboa, DGES/MCTES e CIES.

Nunes, N (2013), Desigualdades Sociais e Práticas de Ação Coletiva na Europa, Lisboa, Mundos Sociais.

Pires, RP; Pereira, C; Azevedo, J; Ribeiro, AC (2014), Emigração Portuguesa. Relatório Estatístico 2014, Lisboa, Observatório da Emigração e Rede Migra, Instituto Universitário de Lisboa (ISCTE-IUL), CIES-IUL, e DGACCP. 